conclusions of the behaviour of the element within the soil are given. Frequently these conclusions are not supported by the data quoted; for example, in Chapter 6 it is stated "in the majority of cases a tendency toward an increase in the content of fluorine in the subsoil was noted". However, in only two of the nineteen profiles presented (Table 20) is there an increase of fluorine in the subsoil. In the remaining seventeen examples quoted there is a decrease.

The behaviour of the elements tin, tungsten, radium, uranium, thorium, ionium, beryllium, scandium, gallium, indium, thallium, germanium, niobium, tantalum, antimony, bismuth, mercury, rhenium, gold, silver, platinum, tellurium and hafnium is briefly mentioned without introducing new data. A comprehensive bibliography contains 560 references, including many non-Russian papers.

Poor editing in the original Russian edition of the book is reflected in the English translation. Numerous errors appear in both the text and tables. Data have not been uniformly presented in some tables and often the units used are not clearly stated. The text on $p$. 170 should follow that on p. 167.

Despite the many editing errors, the extensive tables should prove useful sources of information on the normal contents of the minor elements in soils of the zonal types considered. A. H. Debnam

\section{NUCLEAR RESEARCH IN THE U.S.S.R.}

Atomic Energy in the Soviet Union

By Arnold Kramish. Pp. $x+232$. (Stanford, Calif. : Stanford University Press; London: Oxford University Press, 1960.) 27s. 6d. net.

7 HIS book by Arnold Kramish performs a most The writer traces the published evidence of Soviet activity in the field of nuclear studies since before the War, and indeed he pays rather special attention to the important time of development in the early part of the 1930-40 decade. With some hesitation in the midwar years only, he is able to establish a consistency and breadth of Soviet effort in the field that is altogether impressive. Many scientists who have neglected until recently the original Soviet publications will find the volume a considerable help in tracing some of the important landmarks in Soviet achievement in this field during the past thirty years.

During this time, as the author demonstrates, there have been many vagaries in the policy of the Soviet Union regarding the extent to which publicity has been given to particular advances. The book removes much of this difficulty, and the picture that emerges is one of almost uninterrupted pressure on the large number of well-trained scientists and ongineers to make full use of the generous provision of support in both money and materials. As the author points out, our picture is still far from complete because of the secrecy that still surrounds many of the ventures. He points to interesting differences in approach to certain topics for example to the subject of controlled thermonuclear research. It appears to be the policy to be frank in those areas where really fundamental difficulties are present and so to encourage help to come from any possible source. It is no doubt rewarding to ponder on some of these basic differences in approach.
If one has to make any general conclusion from the study it is probably that achievement by scientists and engineers in the Soviet Union, the United States, and Great Britain is more or less proportional to the support afforded and relatively independent of the political background, provided that original thinking or inventiveness is encouraged.

The style of the author is lively and fresh, and the book is very easily digested by those with some background knowledge of modern physics and atomic energy. Its value to scientists, engineers and administrators is obvious, and it can be highly commended. The price is relatively modest at $27 s .6 d$, and the volume does not suffer from the absence of illustrations.

S. C. Curran

\section{PHYSIOLOGY OF MARINE ANIMALS}

The Biology of Marine Animals

By J. A. Colin Nicol. Pp. xi +707 . (London: Sir Isaac Pitman and Sons, Ltd., 1960.) 95s. net.

$7 \mathrm{O}$ those, of whom I am one, who for the past generation and more have worked in the field of comparative physiology of marine animals, this book comes as a revelation of the extent of achievement during this period. Very few of the 1,700 odd references to literature which are among the many virtues of this volume deal with papers earlier than the midtwenties. It was in that earlier post-war period that the attention of marine biologists began to turn from description, of structure or of life-history, to analysis of function and to the elucidation of physiological as well as of morphological adaptation. Increased knowledge of marine environments went hand in hand with greater understanding of the internal fluid medium in animals and of how problems of osmoregulation had been solved. Interest extended from the properties of vertebrate hæmoglobin to those of hæmocyanin and of other invertebrate respiratory pigments, as well as to the wider general problems of animal pigments so wonderfully displayed in many marine animals. Then also knowledge of the complexities of the mechanisms of sensation and response began to include analysis of the sense organs and behaviour of marino invertebrates and fishes as well as of the nature of nervous and hormonal control particularly in fishes, cephalopods and crustaceans.

In this impressive volume of 700 pages, Dr. Nicol summarizes the results of these investigations, to which he has himself made very significant contributions. It is a major work of synthesis ; it may well be the last time that anyone will attempt singlehanded to cover so wide a field, in any event with that meticulous reference to the sources of knowledge here provided. It does not seem that this book could have been done better. It has been, one knew, years in preparation by an author living in the very atmosphere of marine biological research. It would appear, judging from the date of the introduction, to have been four years in process of publication. So, like all such books, it is a little out of date, a matter, however, that will only be apparent to active research workers and then only within their speciality.

Exception might be taken to the title, but then few people would agree about what precisely is meant by biology. Here it covers physiology, extending from body fluids to luminescence (on which the author writes with particular authority), but with final chapters on "Associations: Commensalism, Para- 